\title{
Retraction Note to: miR-200 Regulates Epithelial-Mesenchymal Transition in Anaplastic Thyroid Cancer via EGF/EGFR Signaling
}

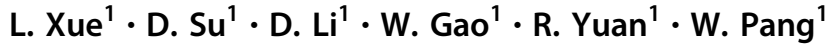

Published online: 30 July 2019

(C) Springer Science+Business Media, LLC, part of Springer Nature 2019

\section{Retraction to:}

Cell Biochemistry and Biophysics (2015) 72:185-190 https://doi.org/10.1007/s12013-014-0435-1

The Editor-in-Chief has retracted this article [1] due to significant overlap with a previously published article by a different author group [2]. The authors have not responded to any correspondence regarding this retraction.
The original article can be found online at https://doi.org/10.1007/ s12013-014-0435-1.

\section{W. Pang}

wuyan_p@163.com

1 Department of Endocrinology, Henan University Huaihe Hospital, Kaifeng 475000, China

\section{References}

1. Xue, L et al. (2015). miR-200 Regulates epithelial-mesenchymal transition in anaplastic thyroid cancer via EGF/EGFR signaling. Cell Biochemistry and Biophysics, 72(1), 185-190. https://doi.org/ 10.1007/s12013-014-0435-1.

2. Zhang, Zhe, et al. (2012). The miR-200 family regulates the epithelial-mesenchymal transition induced by EGF/EGFR in anaplastic thyroid cancer cells. International Journal of Molecular Medicine, 30(4), 856-862. https://doi.org/10.3892/ijmm.2012.1059. 